\title{
Arterial fast bolus flush systems used routinely in neonates and infants cause retrograde embolization of flush solution into the central arterial and cerebral circulation
}

\author{
[Les systèmes de rinçage artériel par bolus rapide, couramment utilisés chez les nouveau-nés et les jeunes enfants, \\ causent une embolisation rétrograde de la solution de rinçage dans la circulation artérielle centrale et cérébrale] \\ Markus Weiss MD, ${ }^{*} \ddagger$ Christian Balmer MD $\nmid \dagger$ Anita Cornelius MD, $\ddagger$ Bernhard Frey MD, ${ }^{\star}$ Urs Bauersfeld MD, $\dagger$ \\ Oskar Baenziger MD*
}

\begin{abstract}
Purpose: To evaluate the risk of retrograde embolization of flush solution in neonates and infants with routinely used electronic syringe pumps and infusion bag pump flush systems.

Methods: With hospital Ethical Committee approval we studied intubated neonates and infants with a 24-GA radial arterial cannula. Fast flush boluses were delivered from the infusion bag pump flush system by opening the flow regulating device for two seconds at bag pump manometre pressures of 100, 200 and $300 \mathrm{mmHg}$. In the syringe pump flush system, fast flush bolus volumes of $0.5,1.0,1.5$ and $2.0 \mathrm{~mL}$ were programmed on the electronic syringe pump and released by opening the flow regulating device for two seconds. A $12-\mathrm{MHz}$ ultrasonic probe placed in the jugular fossa was used to detect white bubbles indicating retrograde embolization of flush solution into the ipsilateral subclavian and common carotid artery.
\end{abstract}

Results: Sixteen patients, aged from I- 105 days (median 22 days) were studied. In all patients retrograde embolization into the subclavian artery was detected at syringe pump bolus volumes of $0.5-1.5 \mathrm{~mL}$ and at 100-200 $\mathrm{mmHg}$ bag pump pressure. In nine of the 16 patients a positive signal was detected in the common carotid artery with 1.5-2.0 mL syringe pump bolus volumes and at 200-300 mmHg bag pump pressure.

Conclusions: In neonates and infants, the standard practice of arterial fast bolus flushing using syringe pump and bag pump flush systems causes retrograde embolization of flush solution into the central arterial and even into the cerebral circulation. The mandatory limitation of fast flush bolus volumes and manometre pressures is urgent in order to reduce retrograde embolization of flush solution and the associated risks in these small patients.
Objectif : Évaluer le risque d'embolisation rétrograde de la solution de rinçage chez les nouveau-nés et les jeunes enfants causée par les systèmes de rinçage avec pompes à seringue électroniques et sacs à perfusion.

Méthode : Ayant obtenu l'approbation du Comité d'éthique de l'hôpital, nous avons pu étudier des nouveau-nés et des jeunes enfants intubés avec une canule artérielle radiale de calibre 24. Des bolus de rinçage rapides ont été libérés par le système de rinçage d'un sac à perfusion en ouvrant le dispositif de régulation de débit pendant deux secondes pour des pressions manométriques du sac de 100, 200 et $300 \mathrm{mmHg}$. Dans le système de rinçage de pompe à seringue, des bolus rapides de 0,5, 1,0, 1,5 et 2,0 mL ont été programmés sur la pompe à seringue électronique et libérés pendant deux secondes. Une sonde à ultra-sons de $12 \mathrm{MHz}$ placée dans la fosse jugulaire a permis de détecter les bulles indiquant une embolisation rétrograde de la solution de rinçage dans les artères sous-clavière et carotide commune homolatérales.

Résultats : Seize patients, de I à 105 jours (moyenne de 22 jours) ont été étudiés. Chez tous les participants, une embolisation rétrograde a été détectée dans l'artère sous-clavière pour des bolus de la pompe à seringue de 0,5 à 1,5 mL et des pressions de 100 et 200 $\mathrm{mmHg}$ du sac à perfusion. Chez 9 des 16 patients, un signal positif a été détecté dans l'artère carotide commune pour des bolus de 1,52,0 $\mathrm{mL}$ et des pressions de 200-300 $\mathrm{mmHg}$.

Conclusion : Chez les nouveau-nés et les jeunes enfants, le rinçage artériel habituel en bolus rapides avec des systèmes de rinçage avec pompe à seringue et sac à perfusion cause une embolisation rétrograde de la solution de rinçage dans la circulation artérielle centrale et même cérébrale. II est urgent de limiter les rinçages en bolus rapides et les pressions au manomètre afin de réduire l'embolisation rétrograde de la solution de rinçage et les risques associés.

From the Departments of Intensive Care and Neonatology, ${ }^{\star}$ Cardiology, $†$ and Anesthesia, $\ddagger$ University Children’s Hospital, Zurich, Switzerland.

Address correspondence to: Dr. Markus Weiss, Department of Anesthesia, University Children's Hospital, Steinwiesstrasse 75, 8032

Zurich, Switzerland. Phone: + 41126673 65; Fax: + 41126679 94; E-mail: markus.weiss@kispi.unizh.ch

Accepted for publication August 29, 2002.

Revision accepted November 29, 2002. 


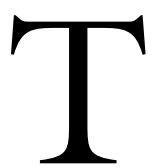

HE use of indwelling arterial cannulas has become standard practice for systemic blood pressure and arterial blood gas monitoring in neonatal and pediatric intensive care and anesthesia. ${ }^{1}$ Arterial catheters are usually flushed continuously with a heparinized solution to prevent occlusion of the cannula. ${ }^{2,3}$ Continuous flushing is commonly provided by a syringe pump or a pressurized infusion bag flush system combined with a flow regulating device. ${ }^{4-9}$ After blood sampling, the arterial pressure line is cleared of blood by irrigation with fluid. This can be performed either with a hand-held syringe or by opening the flow regulating device of a syringe pump or infusion bag pump flush system. Traditionally, handheld syringe flushing is the standard method for purging umbilical artery catheters in newborns. ${ }^{10}$ However, it carries the risk of introducing air, clots and probably micro-organisms into the arterial line when the flushing syringe is connected to the stopcock. In radial and femoral arterial catheters, fast bolus flushing is commonly performed by means of a flow regulating device integrated into the pressure transducer. ${ }^{11-13}$

Among the many events associated with arterial catheterization, retrograde embolization into the central arterial circulation from flushing the arterial cannula carries a substantial risk, particularly in small patients. Retrograde embolization of clots into the central arterial circulation causing cerebrovascular accidents in adults was first described by Gaan et al. ${ }^{14}$ Lowenstein et al. found a high correlation between patient height, minimum volume of flush solution and cerebral embolization. ${ }^{15}$ These results were confirmed in children by Edmonds et al., who reported that a small amount of flush solution $(0.3 \mathrm{~mL})$ injected rapidly, could reach the central arterial circulation in a five-month-old baby with a $57-\mathrm{cm}$ body length. ${ }^{16}$ Ultrasonographic investigations in neonates with radial artery catheters have shown that hand-held syringe flush boluses of $0.5 \mathrm{~mL}$ and $1.0 \mathrm{~mL}$ applied over a one-second period resulted in consistent retrograde embolization of flush solution in the aortic arch and into the left common carotid artery. ${ }^{17}$ If a five-second injection period was used, no positive signal was detected. Using a radioisotope method, even smaller flushing velocities applied manually were reported to cause retrograde flow in preterm babies with radial artery catheters. ${ }^{18}$

Whereas retrograde embolization with hand-held syringe flushing is well established, the risk of retrograde embolization of flush solution with routinely used syringe pump and bag pump flush systems remains unclear. Therefore, the aim of this study was to evaluate the safety of the current practice of flush- ing arterial lines in neonates and small infants with respect to the risk of retrograde embolization of flush solution into the central arterial circulation.

\section{Methods}

We obtained approval of the hospital Ethical Committee to investigate the safety of routine arterial flushing practices in 50 intubated, sedated cardiosurgical neonates and infants with a radial arterial cannula connected either to a bag pump flush system, as routinely used in our pediatric anesthesia unit after cardiac surgery, or to a syringe pump flush system, as used routinely in our intensive care unit. Parental consent was waved by the hospital Ethical Committee since a routine procedure was being investigated by a noninvasive method during routine postoperative echocardiography.

An arterial blood pressure transducer set (Baxter, Ad Uden, The Netherlands) including a flow regulating device integrated into the pressure transducer, a $1.8-\mathrm{m}$ long pressure line and a distal three-way stopcock was used in all patients. The three-way stopcock was followed by $10 \mathrm{~cm}$ of rigid tubing (PE-infusion line, Clinico Medical GmbH, Bad Mersfeld, Germany) which was connected to the 24 -GA radial arterial cannula $(0.7 \times 19$ mm Insyte-W, Becton Dickinson, Sandy, UT, USA).

\section{Syringe pump flush system}

The electronic syringe pump, flushing the line at a flow rate of $1 \mathrm{~mL} \cdot \mathrm{hr}^{-1}$, consisted of a Fresenius Injectomat cp-IS syringe pump (Fresenius AG, Bad Homburg, Germany), a $50-\mathrm{mL}$ infusion syringe (Injectomat ${ }^{\circledR}$ syringe $50 \mathrm{~mL}$, Fresenius AG, Bad Homburg, Germany) filled with heparinized Ringer's solution (1

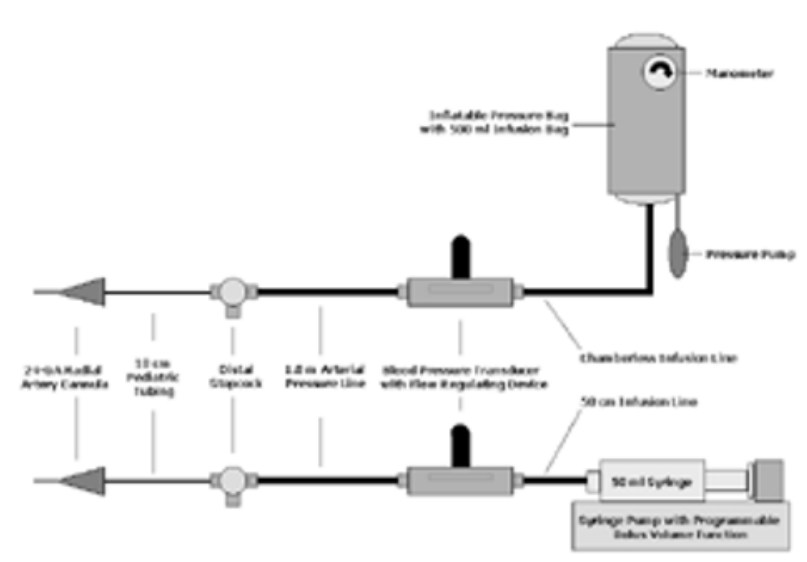

FIGURE 1 Schematic description of the syringe pump and the bag pump flush assembly used for the in vivo measurements. 


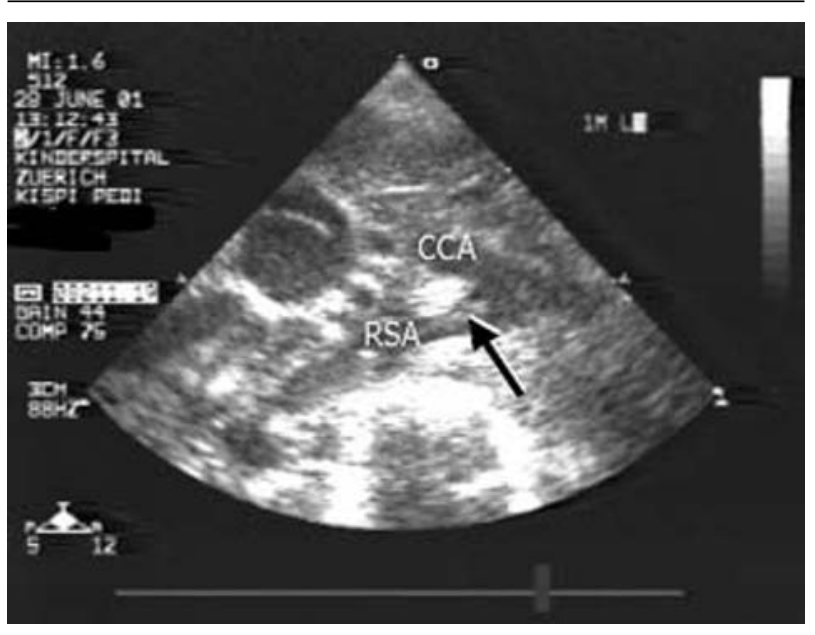

FIGURE 2 Ultrasonic findings in a three-month-old child with retrograde embolization of flush solution as indicated by the visualization of micro-air bubbles (black arrow) in the right subclavian artery during fast bolus flushing from a bag pump flush system pressurized to $300 \mathrm{mmHg} \mathrm{CCA}=$ common carotid artery; $\mathrm{ESA}=$ right subclavian artery.

IU heparin. $\mathrm{mL}^{-1}$; Liquemin ${ }^{\circledR}$, Roche Pharma AG, Reinach, Switzerland) and a 50-cm low-compliance infusion line (PE-infusion line, Clinico Medical GmbH, Bad Mersfeld, Germany) connected to the flow regulating device (Figure 1).

\section{Bag pump flush system}

The pressurized bag flush system comprised an inflatable bag pump (pressure bag $500 \mathrm{~mL}$ - ERKA, Bad Tölz, Germany), and a 500-mL bag of Ringer's lactate (Ecobag - B.Braun Medical AG, Emmenbruecke, Switzerland) with 500 IU heparin attached to an infusion line without drip chamber (Infusion system, Medisize, Hillegorn, The Netherlands) which was connected to the flow regulating device (Figure 1).

\section{Measurements}

In patients with an electronic syringe pump system, bolus volumes of \# $0.5,1.0,1.5$ and $2 \mathrm{~mL}$, as used in routine clinical practice, were programmed and started on the electronic syringe pump. As soon as the initiated bolus volume was reached on the syringe pump display the pressurized bolus volume was released by opening the flow regulating device for a two-second period. In patients with a bag pump flush system, fast flush boluses were delivered by opening the flow regulating device for a two-second period at bag pump manometre pressures of $100,200 \mathrm{mmHg}$ and at a routinely used manometre pressure of $300 \mathrm{mmHg}$. To avoid introducing air bubbles or blood clots into the pressure line, no blood sampling was performed prior to flushing.

Flushing procedures were performed during routine postoperative echocardiography. A $12-\mathrm{MHz}$ ultrasonic probe (Philips, HP 5500 Sonos, The Netherlands) placed in the jugular fossa was used to detect micro-air bubbles in the bloodstream indicating retrograde embolization of flush solution into the right- or left-sided subclavian and common carotid artery (Figure 2). Micro-air bubbles are an ultra-sonographic phenomenon, generated by erythrocytes coated with Ringer's solution or by Ringer's solution itself flushed into the blood stream. As soon as a signal was detected in the common carotid artery, the investigation was stopped in that particular patient with no further increase of bolus volume or bag pump pressure. In addition, mean arterial blood pressure, heart rate, age, body weight and length were recorded.

Data are presented as mean \pm SD as well as median and range if appropriate. Student's t test was used to compare patient characteristics between the syringe pump and the bag pump group. A $P$ value of 0.05 or less was considered to be statistically significant.

\section{Results}

Sixteen cardiosurgical patients (nine patients with syringe pump flush system and seven patients with bag pump flush system) aged from 1-105 days (median 22 days) were studied. Body weight ranged from 2.5-4.5 $\mathrm{kg}(3.5 \pm 0.6)$ and body length from $48-56 \mathrm{~cm}(51.3$ $\pm 1.7)$. Mean arterial pressure was $62.8 \pm 8.1(50-76)$ $\mathrm{mmHg}$. Patient characteristics were not different between groups. Two patients had a left-sided radial 24-GA arterial cannula in place, 14 patients had a right-sided one. Time from insertion of the radial cannula up to the investigation did not exceed more than one day $(0.4 \pm 0.25$ days $)$.

In all patients retrograde embolization of flush solution into the ipsilateral subclavian artery was detected by ultrasonography with syringe pump bolus volumes of $0.5-1.5 \mathrm{~mL}$ and at bag pump pressures of 100-200 $\mathrm{mmHg}$. In nine of the 14 patients with a right-sided arterial radial cannula, a positive signal was detected in the right common carotid artery with $1.5-2.0 \mathrm{~mL}$ syringe pump bolus volumes and at a bag pump pressure of $200-300 \mathrm{mmHg}$ (Table I). In the two patients with left-sided radial arterial cannulation, a syringe pump bolus volume of $1.5 \mathrm{~mL}$ in one patient and a bag pump pressure of $300 \mathrm{mmHg}$ in the other patient resulted in retrograde embolization into the aortic arch, with subsequent flow into the descending aorta. 
TABLE I Ultrasonographic detection of micro-air bubbles in the subclavian and/or the common carotid artery indicating retrograde embolization of flush solution from a right-sided 24-GA arterial cannula during fast bolus flushing using a syringe pump flush system (eight patients) or a bag pump flush system (six patients) is presented as number of positive signals

\begin{tabular}{lll}
\hline $\begin{array}{l}\text { Syringe pump flush system }(n=8) \\
\text { Volume programmed }\end{array}$ & $\begin{array}{l}\text { Positive signal in the Positive signal in the } \\
\text { subclavian artery }\end{array}$ & $\begin{array}{l}\text { common carotid } \\
\text { artery }\end{array}$ \\
& & $0 / 8$ \\
$0.5 \mathrm{~mL}$ & $1 / 8$ & $0 / 8$ \\
$1.0 \mathrm{~mL}$ & $6 / 8$ & $4 / 8$ \\
$1.5 \mathrm{~mL}$ & $8 / 8$ & $5 / 8$ \\
$2.0 \mathrm{~mL}$ & $8 / 8$ & \\
& & \\
Bag pump flush system & $(n=6)$ & \\
Manometre pump & Positive signal in the Positive signal in the \\
pressure & subclavian artery & common carotid \\
& & artery \\
$100 \mathrm{mmHg}$ & $2 / 6$ & $0 / 6$ \\
$200 \mathrm{mmHg}$ & $6 / 6$ & $2 / 6$ \\
$300 \mathrm{mmHg}$ & $6 / 6$ & $4 / 6$ \\
\hline
\end{tabular}

TABLE II In vitro infusion pressures measured proximally to the flow regulating device are shown for different bolus volumes programmed on the syringe pumps prior to purging the arterial line. Measurements were performed in ten different syringe pump/flow regulating device assemblies using an industrial manometre system (Pressure Sensor, PA-35/80797-10; 1-10 bar, Keller AG, Winterthur, Switzerland)

\begin{tabular}{ll}
\hline $\begin{array}{l}\text { Syringe pump flush system } \\
\text { Volume programmed }(\mathrm{mL})\end{array}$ & Infusion pressure $(\mathrm{mmHg})$ \\
\hline 0.5 & $305.2 \pm 65.4$ \\
1.0 & $650.5 \pm 111.7$ \\
1.5 & $1125.1 \pm 282.6$ \\
2.0 & $1676.9 \pm 136.9$ \\
Occlusion alarm & $2048 \pm 262.6$ \\
$(2.38 \pm 0.23 \mathrm{~mL})$ & \\
\hline
\end{tabular}

Data are presented as mean $\pm \mathrm{SD}$.

\section{Discussion}

We have evaluated the risk of retrograde embolization with the use of two standard arterial flush techniques applied routinely in neonates and small infants. The study results clearly demonstrate that routine fast bolus flushing techniques through arterial radial catheters in neonates and infants result in retrograde embolization of flush solution into the central arterial circulation. The findings are consistent with the in vitro results reported earlier for both flush systems. ${ }^{13,19}$

Flow regulating devices have been designed to provide constant flushing of a catheter system and to isolate the compliant fluid reservoir from the transducer to avoid damping of the blood pressure waveform. Such "regulated flow, isolating flushing devices" were first described by Johnson and Ito and Gardner and colleagues. ${ }^{5,6}$ They were developed by the Sorenson Research Company as a disposable device for continuous flushing of catheters which incorporates a "fast flush" facility for clearing the line after blood has been sampled. Now, several flow regulating devices are available from different manufacturers, many of which are incorporated into the invasive pressure transducer. Design and function of such flow regulating devices are described in detail by Latimer and Latimer and McKinney and Orr. ${ }^{4,12}$

Syringe pump flush systems are the standard for neonates and small children. They allow continuous low flow rates of $0.5-1 \mathrm{~mL} \cdot \mathrm{hr}^{-1}$ and the use of measured flush boluses. However, dependent on the volume pressurized, the pressure level of the occlusion alarm and the compliance of the syringe infusion pump assembly, fast flush boluses may be released at pressures of up to $2000 \mathrm{mmHg}$ (Table II). A survey in our neonatal and pediatric intensive care unit revealed that bolus volumes between $\mathrm{l}$ and $2 \mathrm{~mL}$ are routinely preloaded before the flow regulating device is released for cleaning the pressure line. Higher volumes are more effective to purge the catheters.

Infusion bag pump flush systems with flow regulating devices are the standard practice for continuously flushing vascular catheters in adult intensive care and anesthesia. They are rarely used in neonatal and pediatric intensive care because their relatively high continuous flush rate may lead to fluid overload in these often fluid-restricted patients. However, bag pump flush systems, as used in our anesthesia unit, are preferred in some general and cardiac pediatric anesthesia units where the associated higher fluid administration from continuous flushing $\left(3 \mathrm{~mL} \cdot \mathrm{hr}^{-1}\right)$ as compared to syringe pumps $\left(0.5-1 \mathrm{~mL} \cdot \mathrm{hr}^{-1}\right)$ is not a significant issue.

In routine practice, bag pumps are set at a pressure of $300 \mathrm{mmHg}$. Inaccuracy of manometre pressures and additional hydrostatic pressure column my lead to excessive driving pressures in these flush systems. ${ }^{20}$

In contrast to the syringe pump flush systems, in which a highly pressurized small bolus volume is stored and then rapidly released, the bag pump flush system represents a pressurized, volume-unlimited "fluid injector", in which a fluid flow is created and then maintained while opening the flow regulating device. The role of opening times was elucidated and reported in our previous in vitro investigations. ${ }^{19}$

Although the fluid kinetics may be different for the two flush systems, both result in considerably high flow velocities with the associated potential risks. Rapid 
intra-arterial injection of flush solution can dislodge a thrombus from the cannula tip. Dependent on the volume and velocity of the flush bolus, retrograde embolization of flush solution may carry clot aggregates and air bubbles against the arterial blood flow into the central arteries, from where they are further transported by the arterial antegrade blood stream to distal vessels. In fact, the cerebral circulation may become affected as soon as the subclavian-vertebral junction is reached. Retrograde arterial flow, with or without embolization, is suggested as a possible cause of the association between high umbilical artery catheter positioning and cerebral hemorrhage in very low birthweight infants. ${ }^{21}$ The proximity of temporal and axillary artery catheters to the carotid bifurcation should also be considered. ${ }^{22-24}$ Embolization into the arterial splanchnic circulation (superior mesenteric artery), particularly with left-sided radial, umbilical and posterior tibial arterial catheter flushing, is also conceivable. ${ }^{17}$

Rapid flushing not only results in retrograde embolization of flush solution, but also causes local arterial vasospasm, possible damage to the pressure transducer sensor, and transient elevation of arterial blood pressure and intracranial/intraventricular pressure. ${ }^{17}$ This is likely to be important in the pathogenesis of intraventricular hemorrhage, particularly in infants with preceding asphyxia and associated pressure-dependent blood flow. ${ }^{25-27}$ In addition, it has been suggested that embolization of cold fluid into a vascular bed causes vasospasm, particularly in an abnormally sensitive arterial system or with the accidental use of very cold fluid. ${ }^{15}$

It is also conceivable that rapid central venous line flushing can result in elevation of right atrial pressure with the risk of paradoxical embolism through a patent foramen oval or an atrial septal defect, a phenomenon used to diagnose right-to-left shunts during echocardiography. ${ }^{28}$

Because of the constant findings of retrograde embolization of flush solution into the central arterial and even into the cerebral circulation with our routine practice, the study was stopped after 16 patients. Upper limits for manometre bag pressures as well as syringe pump bolus volumes were reduced. Based on our in vivo and in vitro findings, fast bolus flushing with the syringe pump flush system, should be limited to bolus volumes not higher than $0.5 \mathrm{~mL}$. With a bag pump flush system, pressures should be limited to $150 \mathrm{mmHg}$ and short ( $\leq$ one second) opening periods should be used for fast bolus flushing in neonates and infants. ${ }^{20}$

This study only focussed on one type of flow regulating device. Fast flow velocities from other flow regulating devices may be higher than reported and may vary considerably between different brands. ${ }^{13}$ Furthermore, the study did not investigate the influence of arterial blood pressure and other patient characteristics on retrograde embolization. However, our results should be representative of neonates and infants up to three months of age.

For safety reasons, flush tests were performed without prior aspiration of blood. The different viscosity of blood and Ringer's solution may have resulted in different findings. However, exclusive flushing of Ringer's solution through the cannula is common, particularly when the arterial waveform is abnormal.

In summary, routine flushing of arterial lines in neonates and infants using flow regulating devices combined with pressurized syringe pumps or bag pump flush systems results in the retrograde embolization of flush solution into the central arterial and even into the cerebral circulation. Limitation of bolus volumes in syringe pump flush systems, as well as limitation of infusion pressures and duration of flushing with bag pump flush systems, are required to prevent retrograde embolization of flush solution and the associated risks in these small patients.

\section{References}

1 Cilley RE. Arterial access in infants and children. Semin Pediatr Surg 1992; 1: 174-80.

2 Sellden H, Nilsson K, Larsson LE, Ekstrom-Jodal B. Radial arterial catheters in children and neonates: a prospective study. Crit Care Med 1987; 15: 1106-9.

3 Wessling KH, Ty Smith N. Availability of intraarterial pressure waveforms from catheter-manometer systems during surgery. J Clin Monit 1985; 1: 11-6.

4 Latimer RD, Latimer KE. Continuous flushing systems. A critical review. Anaesthesia 1974; 29: 307-17.

5 Johnson DG, Ito T. Continuous flush of arterial pressure-recording catheters. A safe and inexpensive system. J Thorac Cardiovasc Surg 1969; 57: 675-8.

6 Gardner RM, Warner HR, Toronto AF, Gaisford WD. Catheter-flush system for continuous monitoring of central arterial pulse waveform. J Appl Physiol 1970; 29: 911-3.

7 Meyer CL, Gresham EL, Moye L, Jansen RD, Lemons JA, Schreiner $R L$. Evaluation of a system for continuous neonatal blood pressure monitoring. Crit Care Med 1982; 10: 689-91.

8 Haselby KA, Dierdorf SF. A gravity-driven continuous flush system for vascular catheters. Anesth Analg 1982; 10: 871-2.

9 Gardner RM, Bond EL, Clark JS. Safety and efficacy of continuous flush systems for arterial and pulmonary artery catheters. Ann Thorac Surg 1977; 23: 534-8.

10 Gardner RM, Parker J, Feinaner R. System for umbili- 
cal artery monitoring. Crit Care Med 1982; 10: 456-8.

11 Oh T, Opie NJ, Davis NJ. Continuous flush system for radial artery cannulation. Anaesth Intensive Care 1976; 4: 29-32.

12 McKinney MS, Orr IA. Characteristics of the pharmaseal continuous flushing device. Anaesthesia 1989; 44: 242-4.

13 Rithalia SVS, Tinker J. Continuous flush devices for vascular pressure monitoring. Intensive Care Med 1983; 9: 295-8.

14 Gaan D, Mallick NP, Brewis RAL, Seedat $\Upsilon K$. Cerebral damage from declotting Scribner Shunts. Lancet 1969; 2: 77-9.

15 Lowenstein E, Little JW III, Lo HH. Prevention of cerebral embolization from flushing radial-artery cannulas. N Engl J Med 1971; 285: 1414-5.

16 Edmonds JF, Barker GA, Conn AW. Current concepts in cardiovascular monitoring in children. Crit Care Med 1980; 8: 548-53.

17 Butt WW, Gow R, Whyte H, Smallhorn J, Koren G. Complications resulting from use of arterial catheters: retrograde flow and rapid elevation in blood pressure. Pediatrics 1985; 76: 250-4.

18 Campbell N, Loughnan PM, Duncan AW. The risk of cerebral embolisation from flushing peripheral artery catheters in the newborn. Austr Paediatr J 1982; 18: 141 .

19 Cornelius A, Fischer J, Frey B, Baenziger O, Gerber AC, Weiss $M$. Pressurised bag pump and syringe pump arterial flushing systems: an unregognised hazard in neonates? Intensive Care Med 2002; 28: 1638-43.

20 Hug MI, Buettiker V, Cornelius A, Weiss M. Variability in infusion pressure and continuous flow rate delivered from pressurized bag pump flush systems. Anaesth Intensive Care 2002; 30: 341-7.

21 Schick JB, Beck AL, DeSilva HN. Umbilical artery catheter position and intraventricular hemorrhage. J Perinatol 1989; 9: 382-5.

22 Prian GW, Wright GB, Rumack CM, O'Meara OP. Apparent cerebral embolization after temporal artery catheterisation. J Pediatr 1978; 93: 115-8.

23 Simmons MA, Levine RL, Lubchenco LO, Guggenbeim $M A$. Warning: serious sequelae of temporal artery catheterization. J Pediatr 1978; 92: 284.

24 Moylan SL, Murdoch LJ. A prospective survey of axillary artery cannulation in paediatric intensive care. Paediatr Anaesth 1993; 3: 37-40.

25 Goddard J, Lewis RM, Alcala H, Zeller RS. Intraventricular hemorrhage - an animal model. Biol Neonate 1980; 37: 39-52.

26 Funato M, Tamai H, Noma K, et al. Clinical events in association with timing of intraventricular hemorrhage in preterm infants. J Pediatr 1992; 121: 614-9.

27 Lou HC, Lassen NA, Friis-Hansen B. Impaired autoregulation of cerebral blood flow in the distressed newborn infant. J Pediatr 1979; 94: 118-21.

28 Valdes-Cruz LM, Pieroni DR, Roland JM, Varghese PJ. Echocardiographic detection of intracardiac right-toleft shunts following peripheral vein injections. Circulation 1976; 54: 558-62. 